\title{
Exposure as Collected End Day
}

National Cancer Institute

\section{Source}

National Cancer Institute. Exposure as Collected End Day. NCI Thesaurus. Code C117499.

The final day of the exposure collection period. 